\title{
Managing A Veterinary Practice: A Guide To Organizational Culture In Veterinary Practice
}

\author{
Erik Diez \\ dr.erikdiez@gmail.com \\ Tierärztliches Kleintierzentrum Wahlstedt GmbH, Germany \\ https://doi.org/10.51137/ijarbm.2020.1.1.2
}

\begin{abstract}
The veterinary profession in Germany is undergoing a fundamental change. While the number of small practices is decreasing, the number of larger group, partnership or corporate practices is increasing. This makes competition among veterinarians even greater. But not only the market itself is changing. The humanization of pets, digitalization, and management and marketing practices/services are important factors that must be taken into account when preparing the practice for the future. The problem that arises from this is the lack of skills among graduates and veterinarians in management and business. While corporate culture models are a foundation for large companies, the veterinary profession, especially on a small scale, lacks these fundamental structural elements.
\end{abstract}

Keywords - Management, Human Ressources, Veterinary Medicine, Healthcare Management, Veterinary Economics, Corporate Culture, Organizational Behaviour

\section{Organizational Culture - What It Is About}

There is no company without a corporate culture. Many are unfamiliar with the term corporate culture. It is an essential tool for the management of a company, and closely anchors the culture with the leadership and, above all, the "style" of leadership in the company. By definition, there are many different ways to describe a corporate culture, but none that stands out clearly from others. Corporate culture is often described as organizational culture. 
The corporate culture has a significant impact on the performance of a company and the implementation of innovations of a company. (Macapagal, 2020) Research has shown that the corporate culture is the foundation for success in implementing strategies and plans for the company. Even if the working atmosphere is innovative and supportive, there are still major differences in team performance. (Bower, 2009) From this, one can in part already conclude the crucial importance of a company's culture. The bottom line is that corporate culture, like any other culture, manifests itself primarily in the way people act, think, perceive, evaluate, feel and the way they are "communicated". Therefore it is omnipresent in all situations and events in the company. It results from the norms, values, customs, rules, attitudes and beliefs of the people in a company. What most people are more familiar with, however, are parts that make up a corporate culture. Thus, corporate identity, corporate communications and corporate behaviour can also be counted among the generic terms of corporate culture. (Blättner and Matzner, 2010; Clarke and Chapman, 2012) The most important factors that are described with organizational cultures are: psychological security, reliability, structure and clarity, meaning and impact of work. (Cooper, 2000) Whether a company itself is the culture or has a culture is also a matter of constant debate among experts. It is essential whether the corporate culture is consciously lived openly or subconsciously anchored in each employee, since each employee has his or her own view of the corporate culture. There are currently no studies on corporate cultures in veterinary practices in the German language literature. In the German language literature these topics are only partially represented, only in the English language there are isolated articles on the topic.

\section{$2 \quad$ Analyzing And Shaping The Culture}

When it comes to the question of shaping and changing corporate culture, there are various approaches that can be taken. However, the process of shaping and changing is not a process that can be achieved by immediate change. The process is complex and difficult to control, as it interferes with the basic attitudes and perceptions of all employees in the company. Every employee must first be convinced "himself" before a change can be implemented. Therefore, an analysis of the "actual situation" should be carried out 
first. After all, as in our profession, the diagnosis, i.e. the actual situation, must be determined before therapy can begin. The analysis and implementation of the cultural change is only the first step. Extremely important is the maintenance and constant adaptation of the team / company to the dynamic changes in the practice.

For the analysis of the corporate culture, the 3-level model of organizational culture by Edgar Schein can be used. Figure 1 shows the 3 levels of an organizational culture according to Schein (1985).

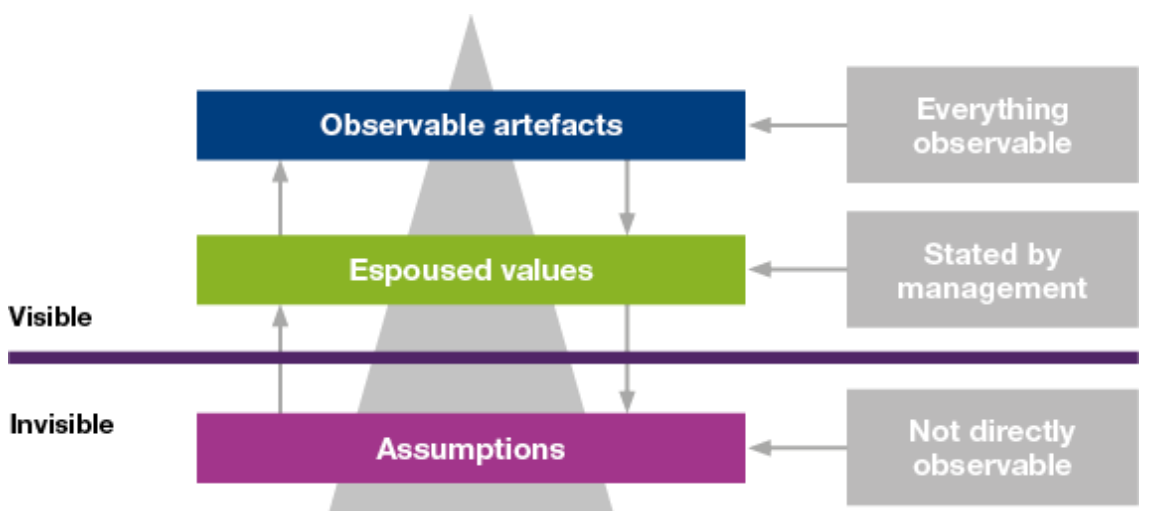

Figure 1: 3 Levels Of Organizational Culture (Source: leadershipcentre.org.uk)

In the following section, I would like to discuss the individual levels of corporate culture and provide them with examples of own analysis results. In a separate study, the corporate culture of a veterinary practice was analyzed and evaluated using an app-based survey and new strategies were implemented. After the new standards, strategies and measures to improve the corporate culture and employee satisfaction were introduced, new data was collected with the same method after 5 months.

\subsection{The Sensory/ Visual Perceptions}

Sensually and visibly perceptible are action patterns and symbols, socalled artifacts. These are outwardly very well represented, but also need interpretation so that the meaning behind them is difficult to access. Examples for visible perceptions are e.g. the corporate identity with logos, flyers, the uniform practice clothing, etc.

To create a healthy corporate culture and promote sustainability, entrepreneurs need to share their vision and strategy with their team. (Ackerman, 2013; Reuter and Thiele, 2011) Online tools or media can support this process. (But et al., 2020) They need to act as a symbol by setting standards through their own behavior and attitudes inside and outside the company. Reflect for yourself, what communicative behavior do your employees/team display? Attention, honesty, politeness towards superiors, employees but also towards customers? Signals such as a lack of honest communication, 
understanding of the company's strategy and vision, as well as declining quality and customer satisfaction are described in this context as threats that act as warning signs. (Brown, 2018; Thiele, 2009) When these warning signals appear, it is the task of the CEO or management to analyze the current culture and improve the company by redesigning the mission and goals. An open and better relationship with its employees is the key to success. (Ackerman, 2013; McGarvey, 1997; Reuter and Thiele, 2011)

Evaluations of own investigations showed that the questions of organizational structures and processes were mostly answered uniformly. This did not change after corporate culture change measures, but on the contrary showed an improvement in the employees' perceptions. Even employees who did not provide clear and uniform answers to the questions of vision and strategy in the first survey showed significantly more uniform answers after a clearly laid out structure of the vision and strategy. The reputation survey offers additional attractive points of view on the existing corporate culture. In the survey, the answers regarding the company's reputation were generally heterogeneous. After an analysis of the company's own reputation using various marketing instruments, this information was presented and showed a better assessment of the reputation of the practice in the follow-up survey. The question whether the own employees would recommend the practice as an employer showed additional discrepancies within the team. While the veterinarians would do so, several of the veterinary technicians were undecided. The investigation of the causes revealed problems such as the planning of shifts of the veterinarians as well as the technician and topics concerning salary and working environment. These problems were deciphered by a restructuring and bonus systems, which was also shown in the 2. surveys. However, it should be mentioned that the salary alone is not a factor for recommendation and problem solving, as can be seen in the following other levels of company culture. An important result of the study was that the need to improve communication within the practice became clear. This was clearly and measurably improved by clearer structures, transparency, as well as joint approaches to solutions by all team members. 


\subsection{Awareness Of Values, Norms and Attitudes}

Collective values form level 2 of the organizational culture. They contain values and norms as well as behavioral guidelines, preferences but also prohibitions. In veterinary practices, these are usually certainly some individual persons who have found certain solutions to problems. Therefore a certain thinking about right and wrong arises among the staff, which is mainly guided by these individual persons. Therefore certain reaction patterns develop. The problem, however, is that these values and norms often lack a logical structure, because they are usually debatable and do not necessarily correspond to the behavior of other team members. In this context, the concept of corporate behavior should be considered. As a core component of corporate behavior, Blättner and Mattzner (2010) describe it as the uniform appearance and behavior of all practice employees. In practice, corporate behavior poses the greatest challenge to the corporate identity of the company. (Blättner and Matzner, 2010)

According to Crowley (2019), the management style of the owner or the supervising veterinarian is one of the most important key factors in employee behavior. (Crowley et al., 2019) There are several key points that the supervisor can consider in order to improve the relationship with the staff. First, the establishment of criteria for interviewing and promoting (potential) employees. (Cake et al., 2016) Second, the behavior of the entire practice team towards each employee. (Reuter and Thiele, 2011) Third, the salary policy and social contributions and incentives for staff to actively contribute ideas to improve and introduce new services in the practice. (Cron et al., 2000) The salary/motivation factor is not proven, as studies have shown that monetary incentives only trigger relatively short-term motivation. But the following question is even more important. Do you really work in a team or do you live a culture of "me against you all"? Various studies indicate that functioning teams generally achieve better results than individual groups of highperforming individuals. However, group norms are the key to team success. These usually contain unwritten and often unspoken rules that determine the behavior of teams. (Adams and Kurtz, 2012) Clear delegation of personnel to their specific work area is of great importance. (Cron et al., 2000) Another important key factor in corporate behavior is the tone of communication, both within the company and externally. Worthy of special mention here is the ability to deal with criticism and the behavior when receiving a complaint towards employees as well as the boss. (Blättner and Matzner, 2010) In addition, corporate behavior includes reacting to the development of human resources (employees), evaluation or feedback from the practice, especially at annual meetings within the practice or externally. (Volk et al., 2018)

The support of the company values as well as the strategy was also evaluated in own analyses. The results showed that the majority of respondents 
supported the company values, while a small proportion (11\%) did not. With regard to strategy, the results showed that a larger proportion of respondents were neutral (67\%) and only 33\% agreed with supporting the corporate strategy. All employees generally shared the same values of the company, but when it came to the company's strategy, the survey showed that veterinarians generally supported the strategy and veterinarians were more undecided. This improved significantly in the surveys after a joint redesign of the strategy.

\subsection{Fundamental Assumptions And Beliefs}

Fundamental assumptions and beliefs form the third and deepest level of organizational culture. They include relationships to the environment, including social relationships, and to human nature. They are invisible and unconscious and are difficult to detect. I would like to give you an example of this. The classical stable and long-established practice, with a stable customer base and a consistent course. The employees work in a certain way, which has "proved itself". One assumes that the processes work in this way and that they now become a matter of course. Alternatives are not asked or recognized. If now "new" alternatives are shown, these are usually rejected directly and partly unfortunately still sanctioned. This is a basic problem, because certain values of level 2 change smoothly into level 3 without being reflected consciously. What follows is an incorporation into the basic assumptions of a person.

When employees feel that their contribution in the workplace is fundamental and they are satisfied with their workload, they feel committed to the company and in return they improve the quality of the services and products offered. In this way, they improve their overall performance within the company. (Dodge et al., 2019) Looking at examples of the greatest threats to a corporate culture, these are usually feelings of "us versus them" between employees and management, and difficulties in recruiting new employees due to a poor reputation. (McGarvey, 1997) Other warning signs include increased employee turnover, difficulty in hiring new professionals, arriving and leaving the workplace on time, and low attendance at company or team meetings. (Clarke and Chapman, 2012)

Own results showed that the veterinarians within the company are generally more satisfied with the workplace. This could be due to the low appreciation that customers or other veterinarians have for the work of the technician, which is the foundation of any running veterinary practice. By measures regarding the improvement of the salary as well as the appreciation the satisfaction rate could be improved significantly after a new survey. In general, all employees were of the opinion that they make important contributions to the practice environment. 


\section{Conclusion}

All practices and clinics are different and usually reflect their practice owners and the culture that has been established over time. To run a successful practice, it is crucial to establish a marketing and customer service culture. This should begin with practice owners/managers, who must take a strategic approach to marketing and management. Once management has set the direction, it is a matter of establishing the culture within the organization. Once the culture is established, the practice should provide owners with an attitude of continuous improvement. Opportunities should always be provided to create more value for the pet owners and the practice team as a collective. However, the corporate culture is not a "self-runner", it must be constantly corrected. This is particularly difficult given the immense workload of practice owners. Particularly when new employees join the team, managers in the practice should support the practice owner.

Although corporate culture models are usually implemented in large companies, the results of the practical example showed that the survey and analysis of the current corporate culture reveals the most problematic management fields. By analyzing the weak points, these can be evaluated and translated into a problem-oriented approach for the future in order to promote the sustainability of the company. The study has evidently shown that when applying the corporate culture on a small business level, the nonvisible factors (e.g. feelings, values) of each employee can be identified. It helps to structure the company owners and their employees at different levels of the company, not only at the level of large companies, and to provide them with a guideline. The corporate culture at the level of small companies can be particularly important because a healthy and stable culture can promote employee engagement and productivity, while an inadequate culture can actually reduce productivity and growth until the company fails. (McGarvey, 1997) 


\section{$4 \quad$ References}

Ackerman, L. (2013). Blackwell's Five-Minute Veterinary Practice Management Consult (2.). Wiley-Blackwell.

Adams, C. L., \& Kurtz, S. (2012). Coaching and feedback: Enhancing communication teaching and learning in veterinary practice settings. Journal of Veterinary Medical Education, 39(3), 217-228. https://doi.org/10.3138/jvme.0512-038R

Bachynsky, E. A., Dale, V. H. M., Kinnison, T., Gazzard, J., \& Baillie, S. (2013). A survey of the opinions of recent veterinary graduates and employers regarding early career business skills. Veterinary Record, 172(23), 604-604. https://doi.org/10.1136/vr.101376

Blättner, A., \& Matzner, W. (2010). Die gesunde Tierarztpraxis: Marketing und Kommunikation. Enke. https://books.google.hu/books?id=k9141_c9o7oC

Bower, J. (2009). Veterinary Practice Management 3rd Edition (3 edition). John Wiley \& Sons.

Brown, B. R. (2018). The Dimensions of Pet-Owner Loyalty and the Relationship with Communication, Trust, Commitment and Perceived Value. Veterinary Sciences, 5(4). https://doi.org/10.3390/vetsci5040095

But, V., Bulboaca, A., Bolundut, D., Boarescu, P.-M., Bulboaca, A. (2020). Medical Education - From Traditional Learning Methods to ELearning Methods. AMI, 42(1). https://ami.info.umfcluj.ro/index.php/AMl/article/view/756

Cake, M., Bell, M., Williams, J., Brown, F., Dozier, M., Rhind, S., \& Baillie, S. (2016). Which professional (non-technical) competencies are most important to the success of graduate veterinarians? A Best Evidence Medical Education (BEME) systematic review: BEME Guide No. 38. Medical teacher, 38, 1-14. https://doi.org/10.3109/0142159X.2016.1173662

Clarke, C., \& Chapman, M. (2012). BSAVA Manual of Small Animal Practice Management and Development (1 edition). British Small Animal Veterinary Association.

Cooper, E. A. (2000). Corporate culture and performance: Relating concepts and outcomes. https://doi.org/10.31274/rtd-180813-13575

Cron, W., Slocum, J., Goodnight, D., \& Volk, J. (2000). Executive summary of the Brakke management and behavior study. Journal of the American Veterinary Medical Association, 217, 332-338. https://doi.org/10.2460/javma.2000.217.332

Crowley, S. L., Homan, K. J., Rogers, K. S., Cornell, K. K., Olavessen, L. J., Charles, E. M., \& Shaw, D. H. (2019). Measurement of leadership skills development among veterinary students and veterinary professionals participating in an experiential leadership program (the Veterinary Leadership Experience). Journal of the American Veterinary Medical Association, 255(10), 1167-1173. https://doi.org/10.2460/javma.255.10.1167 
Dodge, L. E., Koontz, S. R., \& Hadrich, J. C. (2019). Factors associated with financial performance of independently owned companion and mixed animal veterinary practices. 255(7), 805-811. https://doi.org/10.2460/javma.255.7.805

Macapagal, J. (2020). Applications of Teledentistry during the COVID-19 $\begin{array}{lll}\text { Pandemic Outbreak. AMI, 42(3), 133-141. } & \text {. }\end{array}$ https://ami.info.umfcluj.ro/index.php/AMl/article/view/783

McGarvey, R. J. (1997, November 1). Culture Clash. Entrepreneur. https://www.entrepreneur.com/article/14818

Reuter, H.-J., \& Thiele, S. (2011). Die gesunde Tierarztpraxis: Mitarbeiterführung und Motivation. Enke Verlag.

Thiele, S. (2009). Die gesunde Tierarztpraxis: Kundenorientierung und Positionierungsstrategien. Enke Verlag.

Volk, J. O., Schimmack, U., Strand, E. B., Lord, L. K., \& Siren, C. W. (2018). Executive summary of the Merck Animal Health Veterinary Wellbeing Study. Journal of the American Veterinary Medical Association, 252(10), 1231-1238. https://doi.org/10.2460/javma.252.10.1231 